\title{
Título da página: European Transgender Network
} URL: http://tgeu.net/

\section{Ana Cristina Santos}

\section{OpenEdition}

\section{Journals}

Edição electrónica

URL: http://journals.openedition.org/rccs/884

DOI: $10.4000 /$ rccs.884

ISSN: 2182-7435

\section{Editora}

Centro de Estudos Sociais da Universidade de Coimbra

Edição impressa

Data de publição: 1 dezembro 2006

Paginação: 149

ISSN: 0254-1106

Refêrencia eletrónica

Ana Cristina Santos, «Título da página: European Transgender Network», Revista Crítica de Ciências Sociais [Online], 76 | 2006, posto online no dia 01 outubro 2012, consultado o 22 setembro 2020. URL : http://journals.openedition.org/rccs/884 ; DOI : https://doi.org/10.4000/rccs.884 


\section{Espaço Virtual}

\section{Título da página: GLBTQ - Encyclopedia of Gay, Lesbian, Bisexual, Trans- gender and Queer Culture URL: http://www.glbtq.com/}

Inaugurada em Março de 2003, esta página constitui a mais extensa enciclopédia virtual sobre cultura LGBT e queer, com contributos de artistas, académicos e outros profissionais divididos por duas mil entradas organizadas em três grandes tópicos: arte, literatura e ciências sociais.
Outras secções da página incluem um fórum de discussão de acesso livre sobre áreas específicas de interesse, entrevistas com artistas e activistas, recursos audiovisuais e uma lista de publicações temáticas.

\section{Título da página: European Transgender Network URL: http://tgeu.net/}

A página desta federação europeia de grupos e associações transgénero reúne informações detalhadas sobre a situação do transgenderism em muitos países europeus, disponibilizando dados actualizados sobre as principais reivindicações e medidas políticas levadas a cabo por activistas e governos. Para além dos documentos fundadores desta rede, é ainda facilitada informação acerca das principais campanhas desenvolvidas, bem como ligações para grupos e associações nacionais.

\section{Título da página: Gay, Lesbian and Straight Education Network URL: http://www.glsen.org/cgi-bin/iowa/all/home/index.html}

Embora centrada nos Estados Unidos da América, esta página disponibiliza importantes recursos pedagógicos - para docentes e estudantes - sobre o combate à discriminação em meio escolar. Estão acessíveis artigos referentes a políticas sociais, grupos locais, estudos académicos, relatórios nacionais e iniciativas de estudantes. Há ainda uma biblioteca virtual organizada por temas, na qual se pode aceder a artigos e manuais para formação de formadores.

\section{Título da página: ILGA Europa URL: http://www.ilga-europe.org/}

De acesso simples para qualquer utilizador/a, a página da delegação europeia da International Gay and Lesbian Association (ILGA) agrega informações detalhadas sobre a situação dos direitos LGBT em todos os países europeus, aprofundando temas como asilo e imigração, casamento civil entre pessoas do mesmo sexo, educa- 
ção e emprego, saúde, uniões de facto ou violência. É possível aceder a informação actualizada sobre as diferentes campanhas levadas a cabo por esta ONG, bem como a uma descrição das diversas celebrações LGBT que se realizam anualmente em países europeus. Pode também aceder-se a publicações regulares, como relatórios anuais, newsletters mensais e comunicados de imprensa, bem como a um resumo de todas as conferências anuais desta ONG que congrega mais de 200 organizações locais.

\section{Título da página: International Gay and Lesbian Human Rights Commission URL: http://www.iglhrc.org}

A International Gay and Lesbian Human Rights Commission (IGLHRC) é uma organização não governamental criada em 1990 por um grupo de activistas russos e norte-americanos. Tendo por objectivo denunciar situações de discriminação em todo o mundo e garantir o respeito pelos direitos humanos de todas as pessoas independentemente da sua orientação sexual ou identidade de género, esta

\section{Título da página: Pride Links URL: http://www.pridelinks.com/}

Trata-se de um extenso directório com mais de oito mil entradas para temas LGBT, remetendo para outras páginas a nível mundial sobre temas como activismo, arte, desporto, direito, educação, entretenimento, etnia, identidade, Internet, mé-
ONG reúne na sua página informação sobre legislação em vigor (especialmente para candidatos/as a pedidos de asilo), publicações recentes, relatórios, recursos pedagógicos em educação para os direitos humanos, apelos internacionais de acção imediata e uma descrição da situação actual em cada região global.

Esta página está disponível em inglês e castelhano.

dia, política, publicações, religião ou saúde, entre outros. A informação agregada neste directório inclui páginas de associações, artigos de jornal, estudos académicos, calendário de eventos ou fóruns de discussão virtual.

\section{Título da página: Queer Resources Directory URL: http://www.qrd.org/qrd/}

Embora a apresentação visual desta página não disponha de características imediatamente apelativas, os conteúdos disponibilizados constituem um importante recurso para quem se interesse por temas queer. Neste directório en- contram-se mais de vinte e cinco mil ficheiros cruzando a temática queer com questões relacionadas com activismo, cultura, família, história, juventude, legislação, media, política, religião, trabalho, saúde, etc. 


\section{Título da página: Queer Theory URL: http://www.queertheory.com}

Organizada em torno de doze grandes temas - academia, arte, corpo, cultura, futuro, história identidade, lugar, política, relações, teorias e outros -, nesta página é ainda possível pesquisar através dos seis índices criados - académico, autor, assunto, livro, nome e organização. Encontra-se disponível informação específica variada, desde anúncios de conferências, artigos integrais, bibliografias temáticas, a dicionários electrónicos, livros publicados e outros recursos.

\section{Páginas de colectivos LGBT portugueses}

Associação Cultural Janela Indiscreta: http://www.lisbonfilmfest.org/

AT - Associação para o Estudo e Defesa dos Direitos à Identidade de Género: http://a-trans.planetaclix.pt/

Clube Safo:

http://www.clubesafo.com/

ILGA Portugal:

http://ilga-portugal.oninet.pt/

não te prives - Grupo de Defesa dos Direitos Sexuais:

http://www.naoteprives.org/
Opus Gay:

http://www.opusgay.org/

Panteras Rosa - Frente de Combate à LesBiGayTransfobia:

http://www.panterasrosa.com/

Ponto Bi:

http://www.pontobi.org/

PortugalGay.PT:

http://portugalgay.pt/

rede ex aequo:

http://ex-aequo.web.pt/ 